\title{
Further nuclear magnetic resonance studies of flavone
}

\author{
Cirilo García-Martínez, Martha S. Morales-Ríos, and Pedro Joseph-Nathan \\ Departamento de Química del Centro de Investigación y de Estudios Avanzados, \\ Instituto Politécnico Nacional, Apartado Postal 14-740, México, D. F., 07000 México
}

\begin{abstract}
The incorporation of $92.7 \%$ of ${ }^{13} \mathrm{C}$ at the carbonyl group of flavone allowed to measure two- and three-bond carbon-carbon coupling constants which range from 1.4 to $3.5 \mathrm{~Hz}$, and to measure two-, three- and four-bond carbon-hydrogen coupling constants which range from 0.3 to $3.8 \mathrm{~Hz}$. A mixture of unlabelled flavone 1 with its $4-{ }^{13} \mathrm{C}$ labelled analogue 2 further allowed to measure one-bond induced isotope shifts of -15.5 and $-16.2 \mathrm{ppb}$ for $\mathrm{C}-3$ and $\mathrm{C}-4 \mathrm{a}$, respectively, and a three bond induced isotope shift of $+3.7 \mathrm{ppb}$ for $\mathrm{C}-1$ '.
\end{abstract}

\section{Introduction}

Natural occurring flavone 1 has been gaining importance due to its antifungal activity [1]. This bioactivity has been associated to the absence of polar groups in the molecule, and therefore the determination of the charge distribution within the skeleton of 1 has been an important goal. The most suitable method to furnish such information is from NMR data, because chemical shifts directly reflect the total charge density at particular nuclei.

In continuation of our [2] ${ }^{1} \mathrm{H}$ - and ${ }^{13} \mathrm{C}-\mathrm{NMR}$ studies of flavone 1 , as well as studies of others [3, 4], we describe the results from measurements of flavone- $-4{ }^{13} \mathrm{C} 2$, which has been prepared in our laboratory and has been measured by Nuclear Magnetic Resonance, since some insight into the structure of the molecule could be obtained by ${ }^{13} \mathrm{C}$-enrichment [5].

\section{Experimental}

The total synthesis of flavone- $4-{ }^{13} \mathrm{C} 2$, having a $92.7 \%{ }^{13} \mathrm{C}$ enrichment, was performed according to a previously reported procedure [6].

${ }^{1} \mathrm{H}$ and ${ }^{13} \mathrm{C}-\mathrm{NMR}$ spectra were recorded on a Varian Associates XL-300GS spectrometer from $0.8 \mathrm{M}$ solutions in chloroform-d containing tetramethylsilane as the internal reference. For induced isotope shift measurements, a mixture containing $40 \mathrm{mg}$ of flavone 1 and $27 \mathrm{mg}$ of flavone- $4-{ }^{13} \mathrm{C} 2$ in $0.6 \mathrm{~mL}$ of chloroform-d was used. The ${ }^{1} \mathrm{H}$ NMR spectra were obtained using a spectral width of $4000 \mathrm{~Hz}, 64 \mathrm{~K}$ data points, a 45 degree pulse angle, an acquisition time of $3.74 \mathrm{sec}$, and a total of 264 transients. The ${ }^{13} \mathrm{C}$ - 
NMR spectra were obtained using a spectral width of $6169 \mathrm{~Hz}, 128 \mathrm{~K}$ data points, a pulse angle of 39 degrees, an acquisition time of $3 \mathrm{sec}$, a relaxation time of $2 \mathrm{sec}$, Waltz-16 modulated decoupling and a total of 1648 transients.

The ${ }^{1} \mathrm{H}-$ and ${ }^{13} \mathrm{C}-\mathrm{NMR}$ data were extracted from spectra of 1, 2 and a mixture composed of $60 \%$ by weight of 1 and $40 \%$ by weight of 2 .

\section{Results and discussion}

The incorporation of a significant amount of ${ }^{13} \mathrm{C}$ into the carbonyl group of flavone enables us to measure several heteronuclear carbon-hydrogen coupling constants $\left[{ }^{\mathrm{n}} \mathrm{J}(\mathrm{C}, \mathrm{H})\right]$ as well as several homonuclear carbon-carbon coupling constants $\left[{ }^{\mathrm{n}}(\mathrm{C}, \mathrm{C})\right]$. In addition several induced isotope shifts become evident when a sample of unlabelled flavone $\mathbf{1}$ is measured in the presence of the $4-{ }^{13} \mathrm{C}$ enriched analogue 2 .

\section{Heteronuclear carbon-hydrogen coupling constants}

The proton signals owing to the aromatic ortho disubstituted ring (A-ring) of flavone 1 appear as a first order four nuclei spin-spin system for which all coupling constants are accurately known [2]. This four proton spin-spin system changes to a heteronuclear [7] first order five nuclei spin-spin system, in which only ${ }^{5} \mathrm{~J}(\mathrm{C}-4, \mathrm{H}-7)$ is missing, when the carbonyl carbon is labelled with ${ }^{13} \mathrm{C}$ as in 2 . The corresponding spin-spin systems of the A-ring of flavones 1 and $\mathbf{2}$ are depicted in Figure 1, which clearly shows the presence of the additional couplings in the case of the labelled molecule 2 . These additional coupling constants are summarized in Table 1.

Table 1

Homonuclear and heteronuclear coupling constants of C-4 in flavone-4- ${ }^{13} \mathrm{C} 2$.

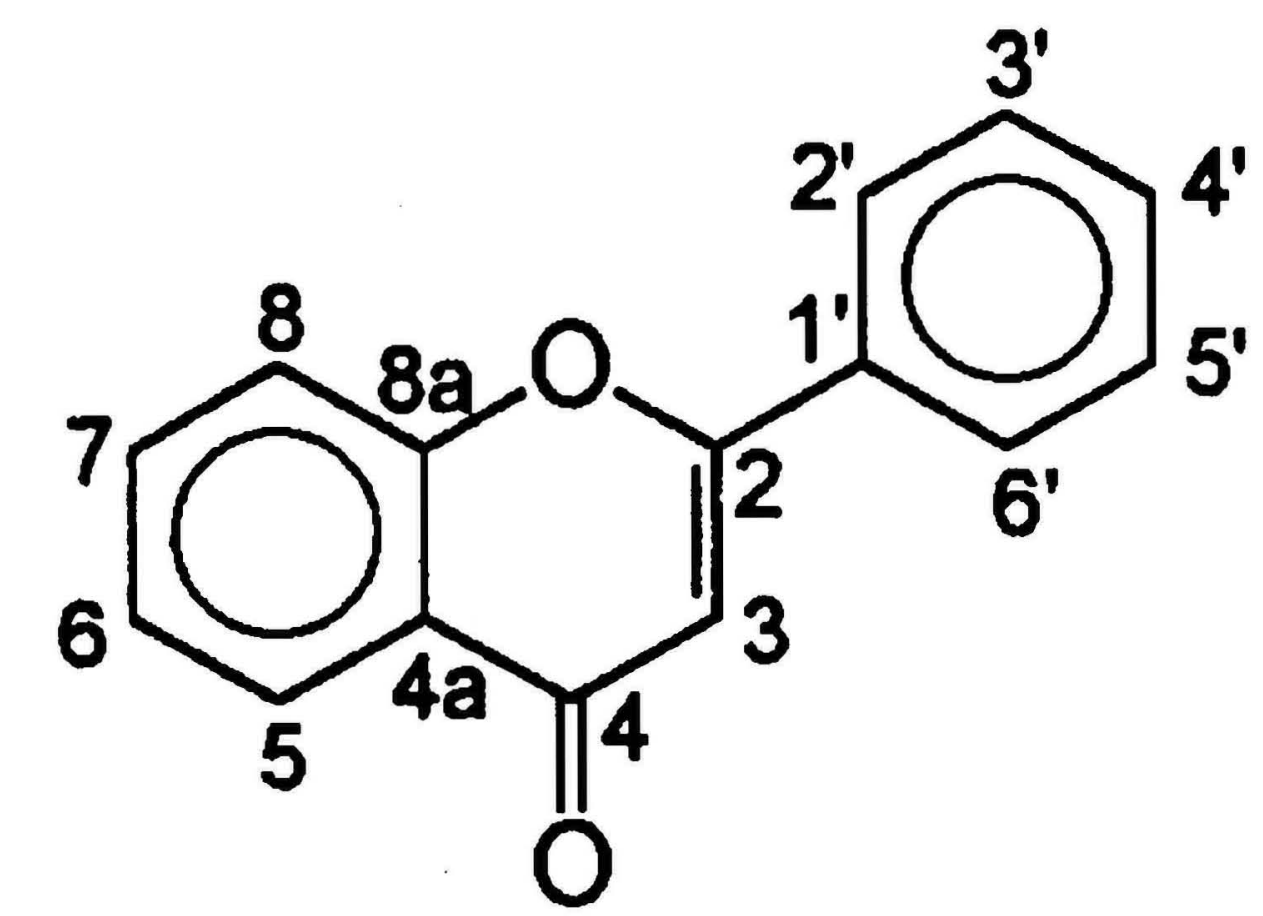

\begin{tabular}{llcccc} 
n & C & $\mathrm{J}(\mathrm{Hz})$ & $\mathrm{n}$ & $\mathrm{H}$ & $\mathrm{J}(\mathrm{Hz})$ \\
\hline 1 & 3 & 57.7 & 2 & 3 & 2.0 \\
1 & $4 \mathrm{a}$ & 54.1 & 3 & 5 & 3.8 \\
2 & $8 \mathrm{a}$ & 1.4 & 4 & 8 & 1.6 \\
3 & 6 & 3.5 & 4 & 6 & 0.3 \\
3 & 8 & 2.0 & & & \\
3 & $1^{\prime}$ & 3.0 & & &
\end{tabular}




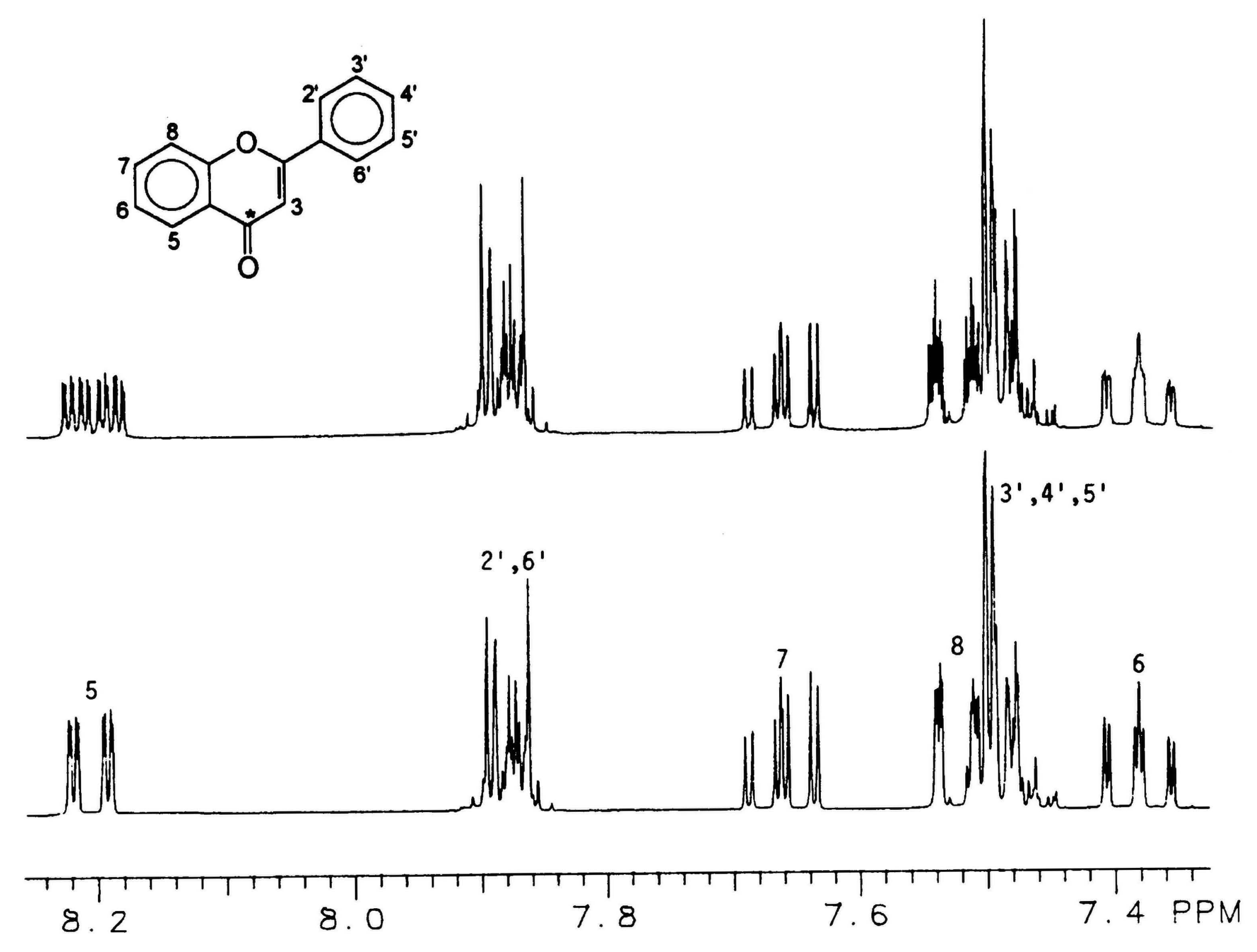

Figure 1. Aromatic region of the $300 \mathrm{MHz}{ }^{1} \mathrm{H}-\mathrm{NMR}$ spectra of flavone (1, bottom trace) and flavone-4 ${ }^{13} \mathrm{C}$ (2, upper trace).

Comparison between ${ }^{3} \mathrm{~J}(\mathrm{C}-4, \mathrm{H}-5),{ }^{4} \mathrm{~J}(\mathrm{C}-4, \mathrm{H}-6)$ and ${ }^{4} \mathrm{~J}(\mathrm{C}-4, \mathrm{H}-8)$ observed for 2 with ${ }^{3} \mathrm{~J}(\mathrm{H}-2, \mathrm{H}-3) .{ }^{4} \mathrm{~J}(\mathrm{H}-2, \mathrm{H}-4)$ and ${ }^{4} \mathrm{~J}(\mathrm{H}-2, \mathrm{H}-6)$ reported for the $\mathrm{AA}^{\prime} \mathrm{BB}^{\prime} \mathrm{C}$ spin-spin system of anisole [8] give similar trends. On this basis, it can be anticipated that the missing ${ }^{5} \mathrm{~J}(\mathrm{C}-4$, $\mathrm{H}-7$ ) in the spectrum of $\mathbf{2}$ must be smaller than the magnet resolution available for the present study (ca. $0.2 \mathrm{~Hz})$.

\section{Homonuclear carbon-carbon coupling constants}

The observed one-, two- and three-bond carbon-carbon coupling constants of 2 are summarized in Table 1 . The ${ }^{1} \mathrm{~J}(\mathrm{C}, \mathrm{C})$ values found for 2 are in agreement with the reported values of aromatic ketones $[9,10]$, as also is the magnitude of ${ }^{2} \mathrm{~J}(\mathrm{C}-4, \mathrm{C}-8 \mathrm{a})$; however ${ }^{2} \mathrm{~J}(\mathrm{C}-4, \mathrm{C}-2)$ and ${ }^{2} \mathrm{~J}(\mathrm{C}-4, \mathrm{C}-5)$ are absent in the spectrum of 2 . Regarding ${ }^{3} \mathrm{~J}(\mathrm{C}, \mathrm{C})$ the values found for 2 have similar trend to those observed [10] for $\alpha$-tetralone- $-1{ }^{13} \mathrm{C}$, showing that the oxygen atom and the carbon-carbon double bond within the benzopyrone moiety do not have significant contribution to the magnitude of ${ }^{3} \mathrm{~J}(\mathrm{C}, \mathrm{C})$. 

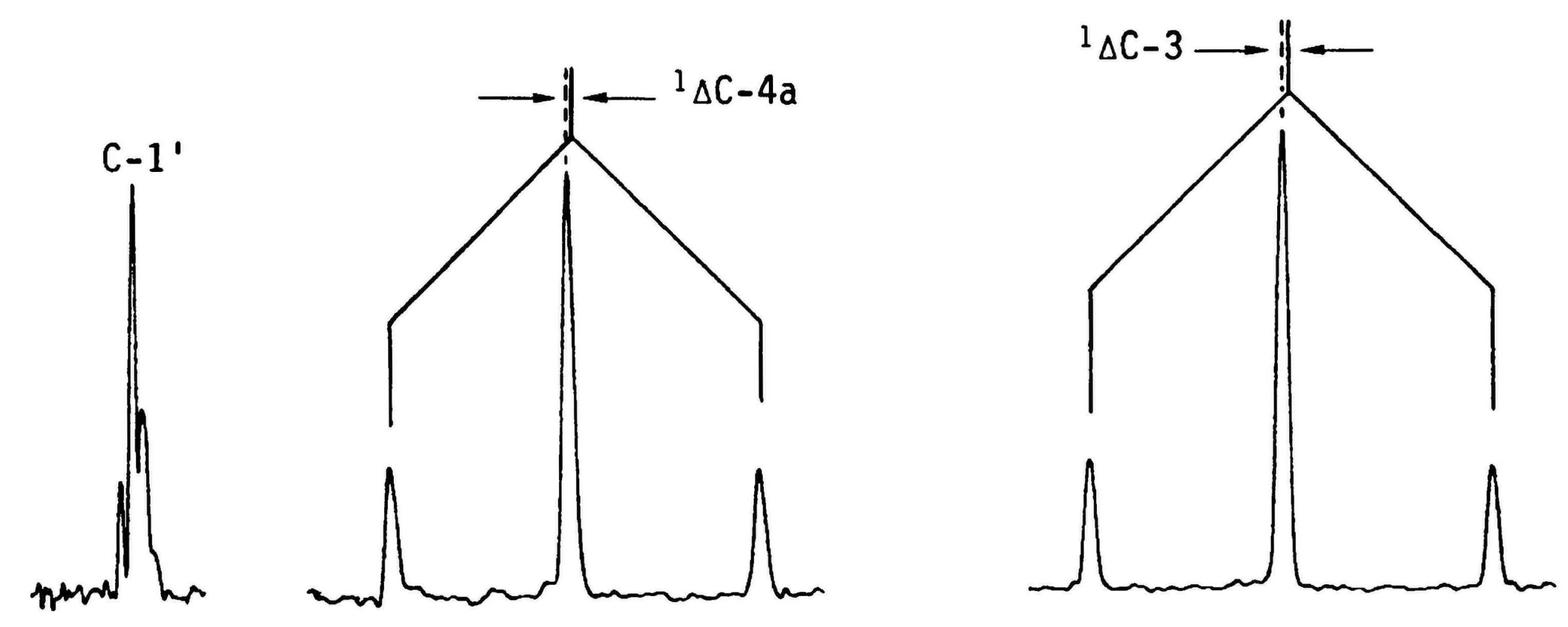

Figure 2. Induced isotope shifts for C-1', C-4a and C-3 in a mixture of flavone 1 and $4-{ }^{13} \mathrm{C}-$ flavone 2.

\section{Induced isotope shifts}

Measurements on a mixture of $\mathbf{1}$ and $\mathbf{2}$ provide the induced isotope shifts depicted in Figure 2, in which the centers of gravity of the doublets arising from 2 are not coincident with the corresponding signal frequencies from 1 . Thus, in accordance to the notation proposed by Gombler [11], flavone shows ${ }^{1} \Delta^{13} \mathrm{C}\left({ }^{13 / 12} \mathrm{C}\right)$ values of -15.5 and $-16.2 \mathrm{ppb}$ for $\mathrm{C}-3$ and C-4a, respectively. This means that these two carbons are more shielded in 2 than in 1 , in agreement with $\Delta^{1}$ values observed in other molecules [12]. In addition a ${ }^{3} \Delta^{13} \mathrm{C}\left({ }^{13 / 12} \mathrm{C}\right)$ value of $+3.7 \mathrm{ppb}$ is observed $\mathrm{C}-1$, which corresponds to a rather large threebond induced isotope shift.

\section{Acknowledgements}

The financial support from CoNaCyT (México) is acknowledged.

\section{References}

[1] M. Weidenböner, H. Hindorf, H. C. Jha, and P. Tsotsonos, Phytochemistry, 29 (1990) 1103.

[2] P. Joseph-Nathan, J. Mares, M. C. Hernandez, and J. N. Shoolery, J. Magn. Reson., 16 (1974) 447.

[3] B. Ternai and K. R. Markham, Tetrahedron, 32 (1976) 565.

[4] A. L. Baumstark, M. Dotrong, R. R. Stark, and D. W. Boykin, Tetrahedron Lett., 29 (1988) 2143.

[5] P. K. Agrawal, R. S. Thakur, and M. C. Bansal, in P. K. Agrawal (Editor), Carbon-13 NMR of Flavonoids, Elsevier, Amsterdam, (1989), p. 70.

[6] F. H. Guidugli, J. Kavka, M. E. Garibay, R. L. Santillan, and P. Joseph-Nathan, Org. Mass Spectrom., 22 (1987) 479.

[7] J. L. Marshall, in A. P. Marchand (Editor), Carbon-Carbon and Carbon-Proton NMR Couplings: Applications to Organic Stereochemistry and Conformational Analysis, Verlag Chemie International, (1993), p. 11.

[8] W. Brügel, in Handbook of NMR Spectral Parameters, Hyden, London, 1 (1979) p. 35.

[9] P. E. Hansen, O. K. Poulsen, and A. Berg, Org. Magn. Reson., 9 (1977) 649. 
[10] R. H. Cox and L. A. Levy, Org. Magn. Reson., 21 (1983) 173.

[11] W. Gombler, J. Amer. Chem. Soc., 104 (1982) 6616.

[12] P. E. Hansen, in G. A. Webb (Editor), Annu. Rep. NMR Spectrosc., 15 (1983) 181. 


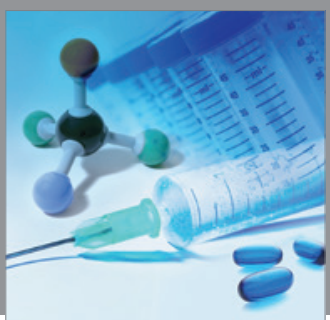

International Journal of

Medicinal Chemistry

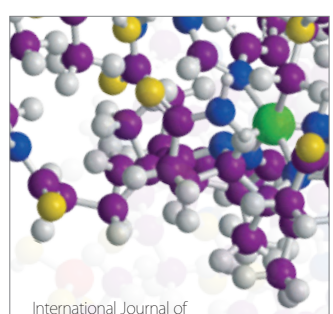

Carbohydrate Chemistry

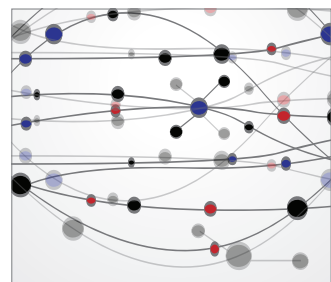

The Scientific World Journal
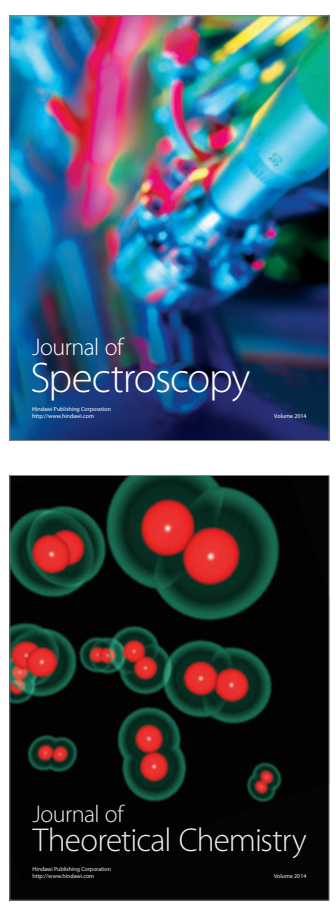
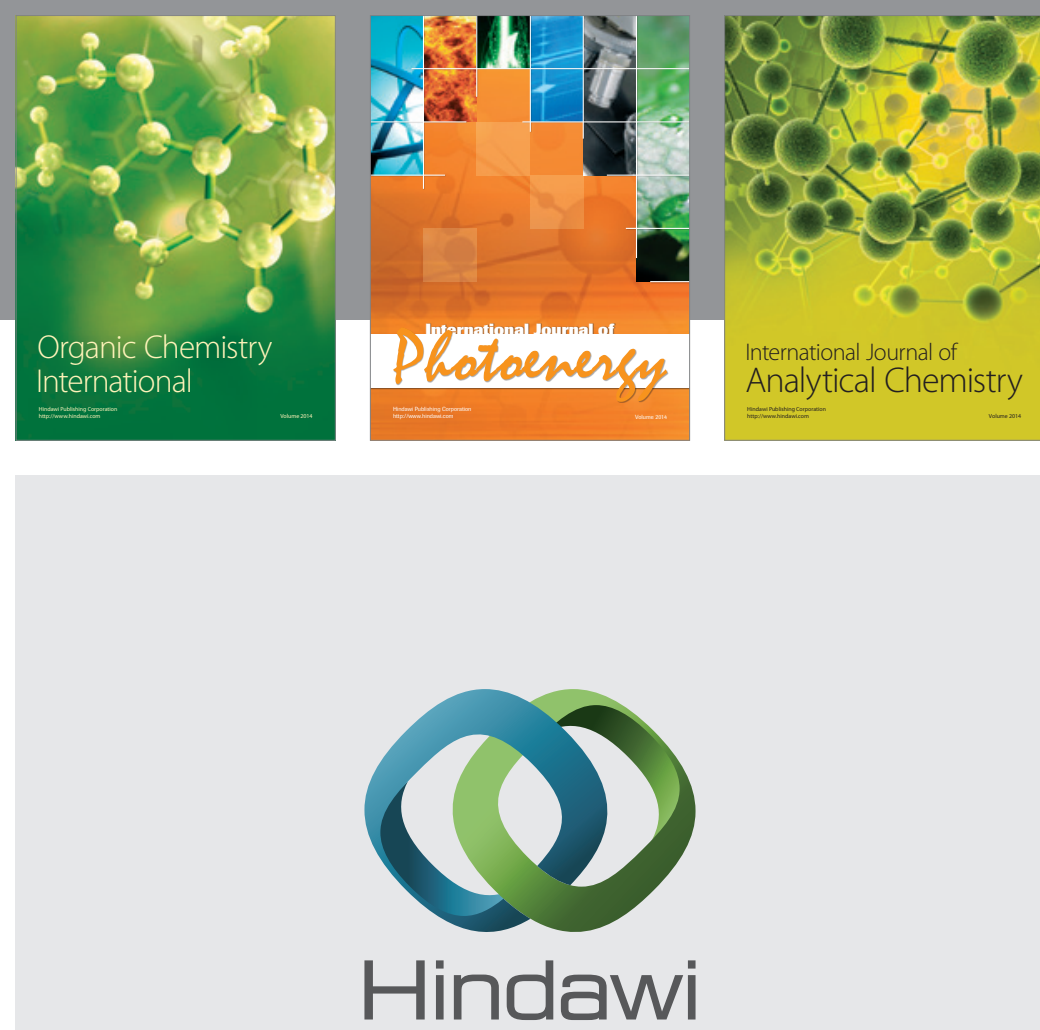

Submit your manuscripts at

http://www.hindawi.com
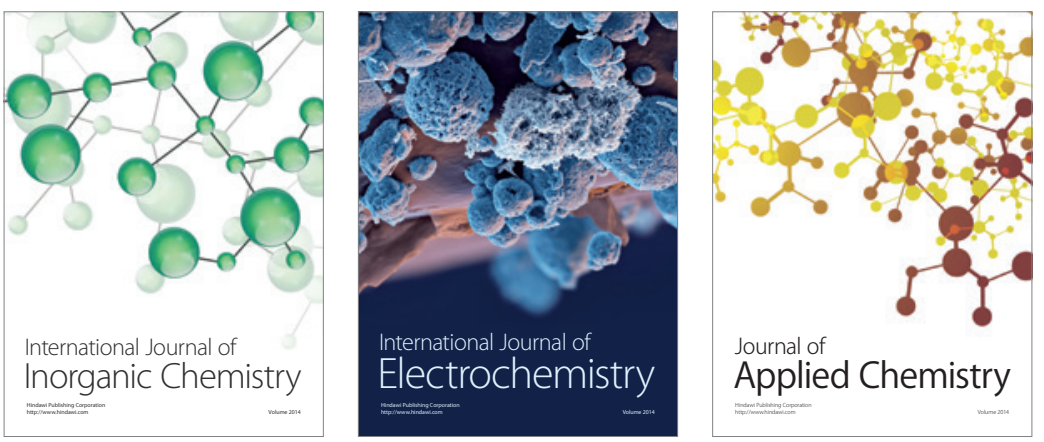

Journal of

Applied Chemistry
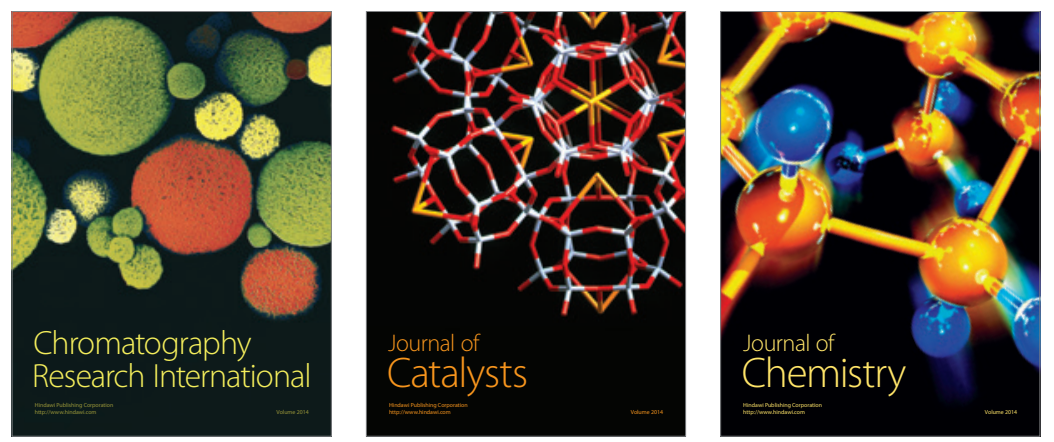
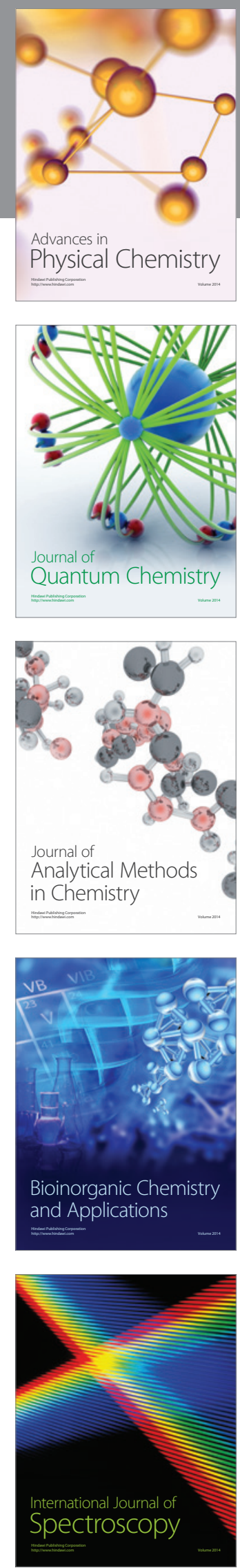